\title{
Optimization of Process Parameters for Pharmaceutical Wastewater Treatment
}

\author{
Chunlei Zhang*, Jingyu Huang \\ Ministry of Education Key Laboratory of Integrated Regulation and Resource Development on Shallow Lakes, \\ College of Environment, Hohai University, \\ No. 1 Xikang Road, Nanjing 210098, China \\ Received: 18 June 2014 \\ Accepted: 16 August 2014
}

\begin{abstract}
Pharmaceutical wastewaters are generated through complex manufacturing processes that contain a variety of organic and inorganic constituents, and are usually characterized by a high concentration of chemical oxygen demand (COD), suspended solids, dissolved solids (salts), toxicity, and refractory compounds. In this paper, wet peroxide oxidation (WPO) was adopted to treat pharmaceutical wastewater. Central composite design, an experimental design for response surface methodology (RSM), was used to create a set of 30 experimental runs needed for optimizing operating conditions. The experimental results show that WPO could effectively reduce COD by $97.5 \%$ at optimum conditions: temperature is $260^{\circ} \mathrm{C}, \mathrm{H}_{2} \mathrm{O}_{2}$ excess (HE) is 0 , the initial concentration of pharmaceutical wastewater is $45,000 \mathrm{mg} / \mathrm{L}$, and reaction time is $10 \mathrm{~min}$. WPO process is possibly suitable for a primary treatment for pharmaceutical wastewater. Response surface methodology (RSM) could be effectively adopted to optimize the operating multifactors in a complex WPO process.
\end{abstract}

Keywords: wet peroxide oxidation, pharmaceutical wastewater, COD removal, response surface methodology, process optimization

\section{Introduction}

Pharmaceuticals present in wastewaters are considered an emerging environmental problem due to their toxicity and chemical persistence in the environment [1]. They can remain in the environment for a long time and their presence is considered dangerous at both low and high concentrations [2-6]. It has been estimated that up to half of the pharmaceutical wastewater produced worldwide is released without any treatment [7]. These pollutants are nonbiodegradable, so application of non-biological processes such as advanced oxidation processes (AOPs) for their destruction will be necessary [8].

Of the various processes that can be used to treat pharmaceutical wastewater, advanced oxidation processes

*e-mail: chunleizhang@hhu.edu.cn
(AOPs) with the capability of exploiting the high reactivity of hydroxyl radicals in driving oxidation have emerged as a promising technology for refractory organic compounds treatment [9]. Several technologies such as Fenton, photoFenton, wet oxidation, ozonation, photocatalysis, etc. are included in the AOPs and their main differences are the source of radicals. Wet peroxide oxidation (WPO) is a kind of AOP developed on the basis of wet oxidation and it is developed in order to decrease the running cost, which is efficient under severe temperature and pressure conditions [10]. It has gained the wide attention of many scholars in recent years [11-13]. Single-factor analysis is employed in the current study of WPO process, but it does not predict optimum conditions well and also does not reveal the interaction between the various operating parameters.

In this paper, important factors and the interaction between the factors for WPO of pharmaceutical wastewater 
by RSM optimization are investigated. RSM is a product of the integration of mathematics and statistics [14-17], which has been widely applied to professional research in biology and statistics, but it is rarely reported in environmental governance, especially in WPO process optimization. RSM can draw the response surface according to some point value and obtain optimal operating points through the analysis of the mathematical model. But the optimal point obtained from traditional methods is only the relatively optimal point of each group in the orthogonal table and is not the optimal overall value of the real.

\section{Experimental}

\section{Apparatus and Method}

All the experiments were performed in a batch reactor. As shown in Fig. 1, the apparatus includes a feed system, preheater, reactor, condenser, gas-liquid separator, and backpressure regulator. WPO of pharmaceutical wastewater was carried out in a $0.7 \mathrm{~L}$ batch autoclave. First, water and pharmaceutical wastewater (concentration was 4,000

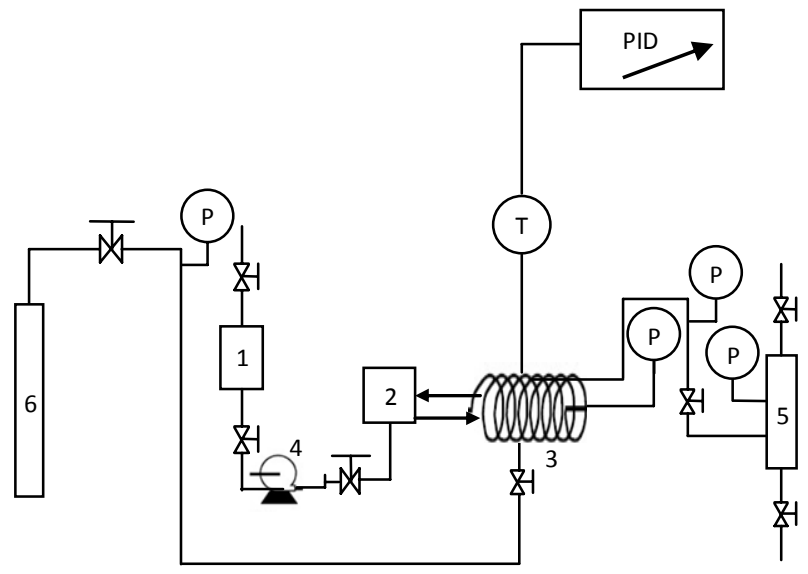

Fig. 1. Schematic diagram of the experimental setup.

1. Oxidant container, 2. Heater, 3. High-pressure autoclave, 4. High-pressure pump, 5. Gas-liquid separator, 6. Nitrogen cylinder

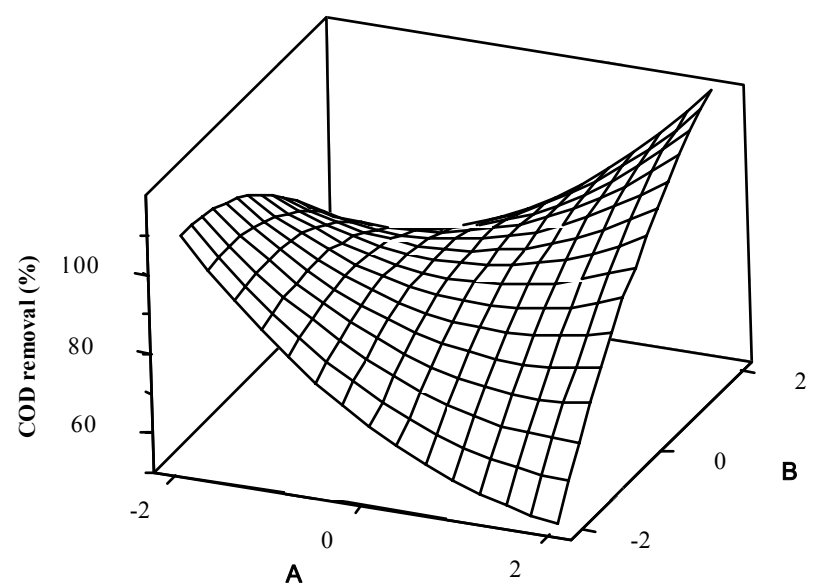

Fig. 2. Response surface plots of the interaction between temperature and initial concentration of pharmaceutical wastewater on COD removal.
Table 1. Factor level.

\begin{tabular}{|c|c|c|c|c|c|}
\hline $\begin{array}{c}\text { Factor } \\
\text { level }\end{array}$ & -2 & -1 & 0 & 1 & 2 \\
\hline $\mathrm{A} /{ }^{\circ} \mathrm{C}$ & 260 & 280 & 300 & 320 & 340 \\
\hline $\mathrm{B} / \mathrm{mg} / \mathrm{L}$ & 10,000 & 20,000 & 30,000 & 40,000 & 50,000 \\
\hline $\mathrm{C} / \mathrm{min}$ & 2 & 4 & 6 & 8 & 10 \\
\hline $\mathrm{D}$ & 0 & 0.25 & 0.5 & 0.75 & 1 \\
\hline
\end{tabular}

$\mathrm{mg} / \mathrm{L}$ ) were put into the reactor, and then the system was flowed by nitrogen to remove the air within the system; the valves around the reactor were closed when the air was removed entirely. Liquid samples (ca. $20 \mathrm{~mL}$ ) were periodically withdrawn from the reactor and analyzed.

\section{Analytical Methods}

The diluted wastewater and COD of the collected liquid are measured by potassium dichromate method of Chinese Standard 11914-89. The HE is defined as equation 1.

$H E=H_{2} \mathrm{O}_{2, \text { Excess }}=\frac{\left(\mathrm{H}_{2} \mathrm{O}_{2}\right)_{\text {in }}-\left(\mathrm{H}_{2} \mathrm{O}_{2}\right)_{\text {stoichiometric }}}{\left(\mathrm{H}_{2} \mathrm{O}_{2}\right)_{\text {in }}} \times 100$

...where $\mathrm{HE}$ is the $\mathrm{H}_{2} \mathrm{O}_{2}$ excess $(\%) ;\left(\mathrm{H}_{2} \mathrm{O}_{2}\right)_{\text {in }}$ is the concentration of hydrogen peroxide fed into the reactor at the beginning of the reaction $(\mathrm{mg} / \mathrm{L}) ;\left(\mathrm{H}_{2} \mathrm{O}_{2}\right)_{\text {stoichiometric }}$ is the stoichiometric requirement concentration of $\mathrm{H}_{2} \mathrm{O}_{2}$ to obtain a complete oxidation of the feed (based on COD) and equal to $[\mathrm{COD}]_{0}$ of pharmaceutical wastewater $(\mathrm{mg} / \mathrm{L})$.

\section{Experimental Design}

The central composite design, an experimental design for RSM, was used to create a set of designed experiments by MINITAB software (version 16). In this paper, the central composite design is selected for 4 factors, i.e. temperature (A), initial concentration of pharmaceutical wastewater (B), reaction time (C), and $\mathrm{HE}(\mathrm{D})$.

Table 1 shows the levels of original and coded factors using central composite design. Table 2 shows central composite design and response value. Given the four main variables and five test levels, 30 experiments were designated by MINITAB software.

\section{Results and Discussion}

\section{Interaction by RSM}

The surface plot of objective function is drawn by Minitab in order to more directly reflect the interaction between the various factors that affect the COD removal and the role of strength for interaction between the various experimental factors. 
Table 2. Central composite design and response value.

\begin{tabular}{|c|c|c|c|c|c|}
\hline Number & A & B & $\mathrm{C}$ & $\mathrm{D}$ & $\begin{array}{c}\text { COD } \\
\text { Removal [\%] }\end{array}$ \\
\hline 1 & 1 & 1 & -1 & -1 & 86.67 \\
\hline 2 & 2 & 0 & 0 & 0 & 94.67 \\
\hline 3 & -2 & 0 & 0 & 0 & 93.44 \\
\hline 4 & 0 & 0 & 0 & 0 & 78.55 \\
\hline 5 & 1 & -1 & 1 & -1 & 69.11 \\
\hline 6 & -1 & 1 & -1 & 1 & 87.11 \\
\hline 7 & 0 & 0 & 0 & 0 & 69.33 \\
\hline 8 & 0 & 0 & -2 & 0 & 78.00 \\
\hline 9 & -1 & -1 & -1 & -1 & 96.00 \\
\hline 10 & 0 & 0 & 0 & 0 & 88.00 \\
\hline 11 & -1 & 1 & -1 & -1 & 96.30 \\
\hline 12 & 0 & 0 & 0 & 0 & 70.00 \\
\hline 13 & -1 & -1 & -1 & 1 & 86.00 \\
\hline 14 & -1 & -1 & 1 & 1 & 96.00 \\
\hline 15 & 0 & -2 & 0 & 0 & 55.00 \\
\hline 16 & -1 & -1 & 1 & -1 & 78.00 \\
\hline 17 & 1 & 1 & 1 & 1 & 96.22 \\
\hline 18 & 0 & 0 & 2 & 0 & 97.88 \\
\hline 19 & 0 & 0 & 0 & -2 & 96.33 \\
\hline 20 & 1 & 1 & -1 & 1 & 97.55 \\
\hline 21 & 0 & 0 & 0 & 0 & 96.33 \\
\hline 22 & 1 & -1 & -1 & -1 & 99.00 \\
\hline 23 & 0 & 0 & 0 & 0 & 98.77 \\
\hline 24 & 1 & -1 & -1 & 1 & 76.33 \\
\hline 25 & -1 & 1 & 1 & -1 & 79.55 \\
\hline 26 & 0 & 0 & 0 & 2 & 82.33 \\
\hline 27 & 0 & 2 & 0 & 0 & 98.22 \\
\hline 28 & 1 & -1 & 1 & 1 & 74.22 \\
\hline 29 & -1 & 1 & 1 & 1 & 69.00 \\
\hline 30 & 1 & 1 & 1 & -1 & 86.00 \\
\hline
\end{tabular}

Figs. 2-7 show the response surface plots for the variations of COD removal according to temperature, initial concentration of pharmaceutical wastewater, reaction time, and HE. In each plot, two factors are varied while the rest is kept constant.

Fig. 2 shows that temperature and initial concentration have obvious effects on COD removal. When temperature is closed to $330^{\circ} \mathrm{C}$ and initial concentration of pharmaceutical wastewater is about $10,000 \mathrm{mg} / \mathrm{L}, \mathrm{COD}$ removal is about $75 \%$. However, temperature is closed to $260^{\circ} \mathrm{C}$ and initial concentration of pharmaceutical wastewater is about $50,000 \mathrm{mg} / \mathrm{L}$ and COD removal is above $90 \%$. Fig. 3 shows that the higher HE, the more obvious COD removal. When HE is closed to 1, COD removal is about $97 \%$. The effect of reaction time on COD removal changes little. Fig. 4

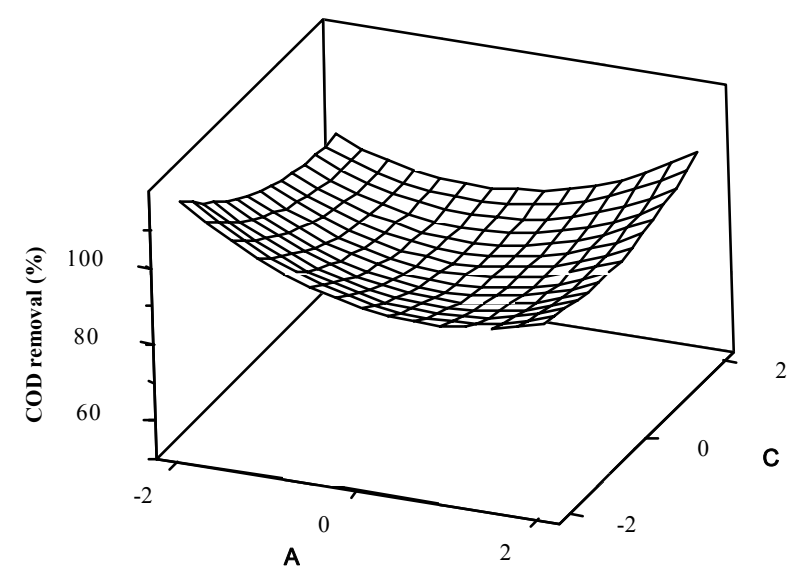

Fig. 3. Response surface plots of the interaction between reaction time and HE on COD removal.

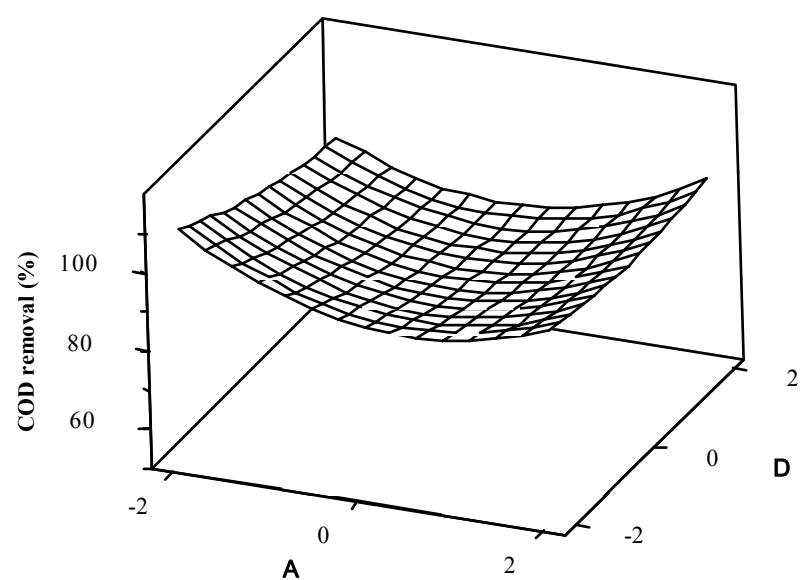

Fig. 4. Response surface plots of interaction between initial concentration of pharmaceutical wastewater and HE on COD removal.

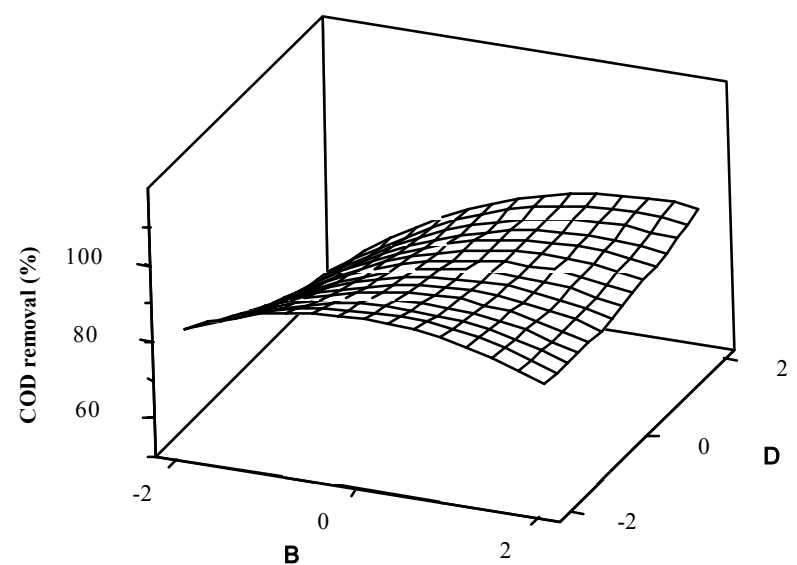

Fig. 5. Response surface plots of the interaction between initial concentration of pharmaceutical wastewater and reaction time on COD removal. 


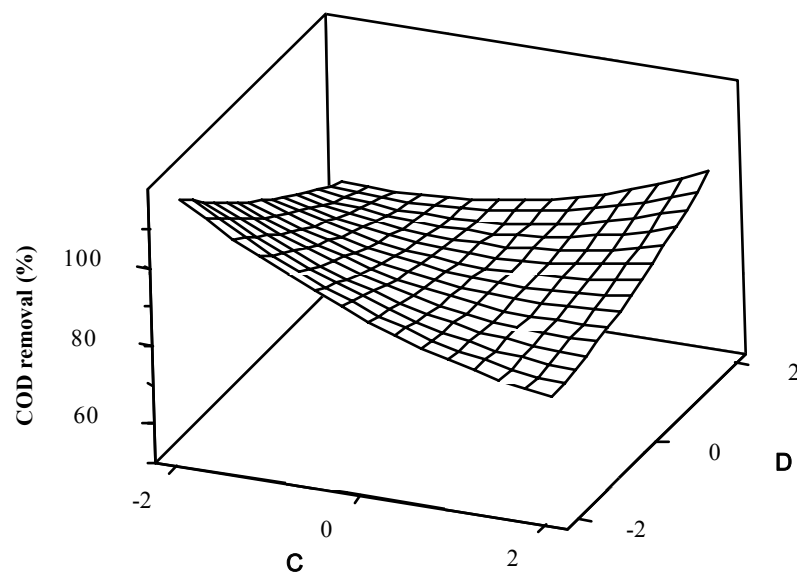

Fig. 6. Response surface plots of the interaction between temperature and HE on COD removal.

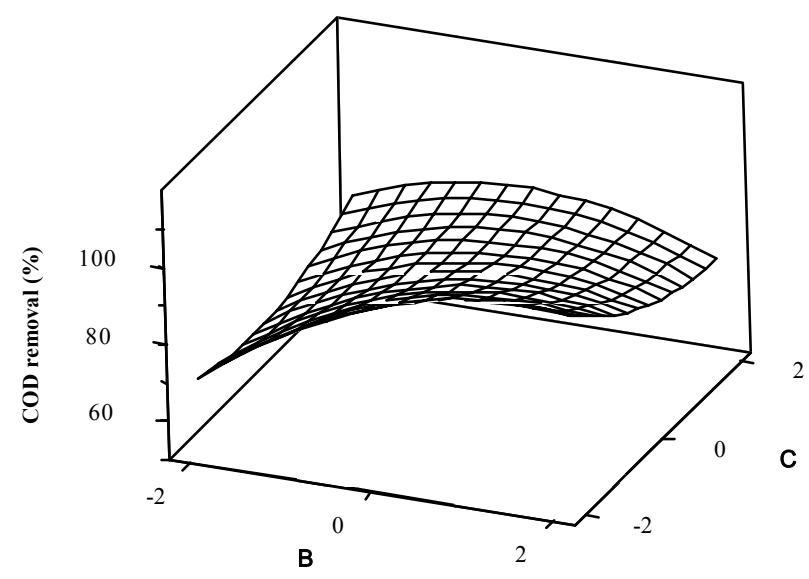

Fig. 7. Response surface plots of the interaction between temperature and reaction time on COD removal. shows a strong interaction between initial concentration of pharmaceutical wastewater and HE. When HE increases, COD removal increases. However, COD removal reduces when initial concentration of pharmaceutical wastewater increases.

Fig. 5 shows that COD removal increases when initial concentration of pharmaceutical wastewater and reaction time both increase. Increased range of reaction time on COD removal is not very obvious. For Fig. 6 it is seen that there is strong interaction between temperature and HE. HE plays the main role in COD removal when temperature changes little. Fig. 7 shows that there is interaction between temperature and reaction time. Increased range of reaction time on COD removal is not very obvious.

\section{Optimization of Process Parameters Using RSM}

Objective function of Minitab's response surface provides an intuitive tool for objective optimization and its unique response optimizer is a powerful tool for multiobjective problem to the solution encountered in the experimental design. And the target function is optimized by Minitab's response optimizer. The result is shown in Fig. 8. It is calculated that the optimized conditions are present: temperature is $260^{\circ} \mathrm{C}, \mathrm{H}_{2} \mathrm{O}_{2}$ excess (HE) is 0 , the initial concentration of pharmaceutical wastewater is $45,000 \mathrm{mg} / \mathrm{L}$, and reaction time is $10 \mathrm{~min}$.

\section{Conclusions}

The WPO process is possibly suitable for a primary treatment of pharmaceutical wastewater. This paper demonstrates

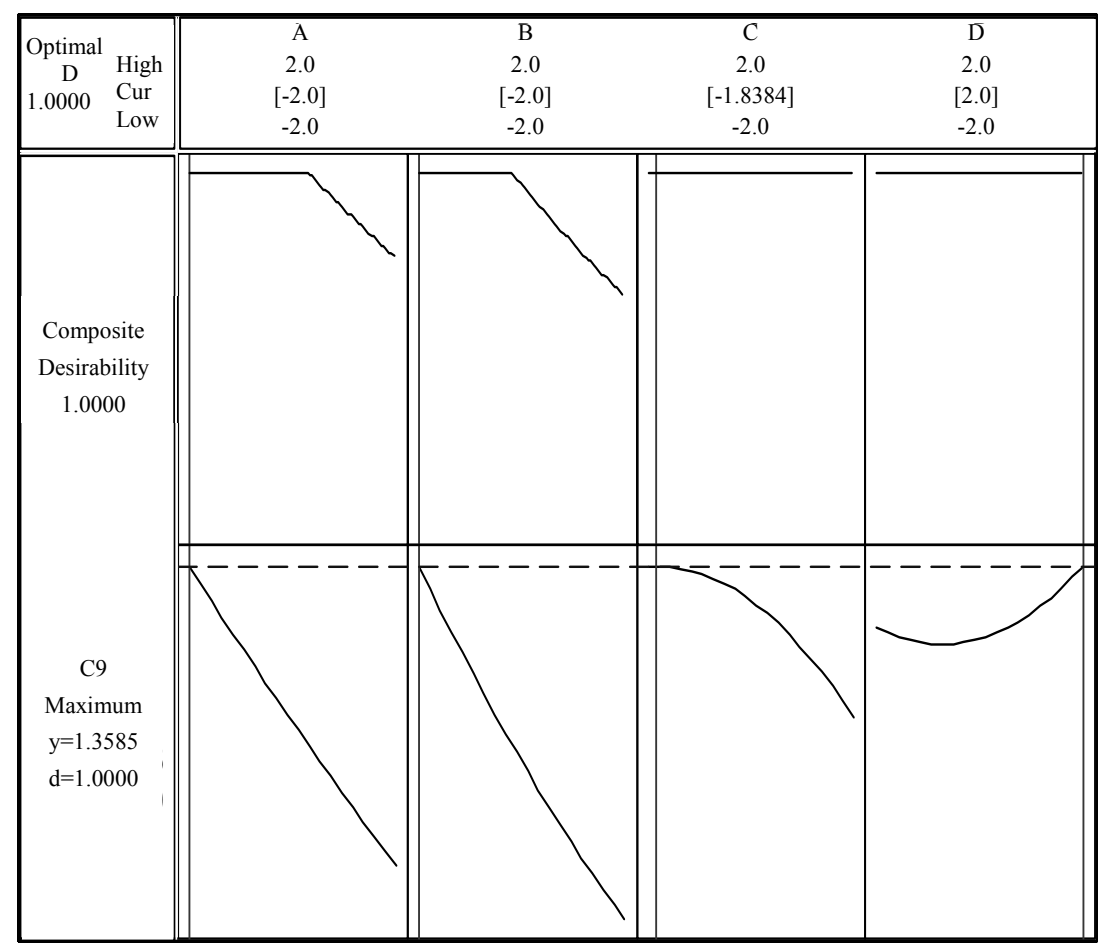

Fig. 8. The optimized result for COD removal by response optimizer. 
that the WPO process is effective in reducing COD by $97.5 \%$. Central composite design provides sufficient data to fit the quadratic models for COD removals. The optimization of the models provides the optimum conditions: temperature is $260^{\circ} \mathrm{C}, \mathrm{H}_{2} \mathrm{O}_{2}$ excess (HE) is 0 , the initial concentration of pharmaceutical wastewater is $45,000 \mathrm{mg} / \mathrm{L}$, and reaction time is $10 \mathrm{~min}$. RSM could be effectively adopted to optimize the operating multifactor in a complex WPO process.

\section{Acknowledgements}

The authors are grateful for financial support from the Natural Science Foundation of China (51108156, 51208177), the special funds on Taihu water pollution control of Jiangsu province (No. TH2013212) and the project funded by the priority academic program development of Jiangsu higher dducation institutions.

\section{References}

1. DEEGAN A.M., SHAIK B., NOLAN N., URELL K., OELGEMÖLLER M., TOBIN J., MORRISEY A. Treatment options for wastewater effluents from pharmaceutical companies. Environ. Sci. Technol., 8, 649, 2011.

2. CHATZITAKIS A., BERBERIDOU C., PASPALTSIS I., KYRIAKOU G., SKLAVIADIS T., POULIOS I. Photocatalytic degradation and drug activity reduction of Chloramphenicol. Water Res., 42, 386, 2008.

3. FATTA-KASSINOS D., MERIC S., NIKOLAOU A. Pharmaceutical residues in environmental waters and wastewater: current state of knowledge and future research. Anal. Bioanal. Chem., 399, 251, 2011.

4. SCHRÖDER H.F. Substance-specific detection and pursuit of non-eliminable compounds during biological treatment of waste water from the pharmaceutical industry. Waste Manage., 19, 111, 1999.

5. VERLICCHI P., AUKIDY M.A., ZAMBELLO E. Occurrence of pharmaceutical compounds in urban wastewater: removal, mass load and environmental risk after a secondary treatment - a review. Sci. Total Environ., 429, 123, 2012.

6. ZIYLAN A., INCE N.H. The occurrence and fate of antiinflammatory and analgesic pharmaceuticals in sewage and fresh water: treatability by conventional and non-conventional processes. J. Hazard. Mater., 187, 24, 2011.
7. ENICK O., MOORE M. Assessing the assessments: Pharmaceuticals in the environment. Environ. Impact. Assess., 27, 707, 2007.

8. KLAVARIOTI M., MANTZAVINOS D., KASSINOS D. Removal of residual pharmaceuticals from aqueous systems by advanced oxidation processes. Environ. Int., 35, 402, 2009.

9. GLAZE W.H., KANG J.W., CHAPIN D.H. The chemistry of water treatment processes involving ozone, hydrogen peroxide and ultraviolet radiation. Ozone-Sci. Eng., 9, 335, 1987.

10. GARCÍA-MOLINA V., LÓPEZ-ARIAS M., FLORCZYK M., CHAMARRO E., ESPLUGAS S. Wet peroxide oxidation of chlorophenols. Water Res., 39, 795, 2005.

11. LOPES R.J.G., PERDIGOTO M.L.N., QUINTA-FERREIRA R.M. Tailored investigation and characterization of heterogeneous $\{\mathrm{Mn}, \mathrm{Cu}\} / \mathrm{TiO}_{2}$ catalysts embedded within a ceria-based framework for the wet peroxide oxidation of hazardous pollutants. Appl. Catal., B, 117-118, 292, 2012.

12. DOMÍNGUEZ C.M., OCÓN P., QUINTANILLA A., CASAS J.A., RODRIGUEZ J.J. Highly efficient application of activated carbon as catalyst for wet peroxide oxidation. Appl. Catal., B, 140-141, 663, 2013.

13. GALEANO L.A., VICENTE M.Á., GIL A. Treatment of municipal leachate of landfill by Fenton-like heterogeneous catalytic wet peroxide oxidation using an $\mathrm{Al} / \mathrm{Fe}$-pillared montmorillonite as active catalyst. Chem. Eng. J., 178, 146, 2011.

14. MUHAMAD M.H., ABDULLAH S.R.S., MOHAMAD A.B., RAHMAN R.A., KADHUM A.A.H. Application of response surface methodology (RSM) for optimisation of $\mathrm{COD}, \mathrm{NH}_{3}-\mathrm{N}$ and 2,4-DCP removal from recycled paper wastewater in a pilot-scale granular activated carbon sequencing batch biofilm reactor (GAC-SBBR). J. Environ. Manage., 121, 179, 2013.

15. LI J., PENG J.H., GUO S.H., ZHANG L.B. Preparation and characterization of electrodeposited $\mathrm{ZnO}$ and $\mathrm{ZnO}: \mathrm{Co}$ nanorod films for heterojunction diode applications. J. Alloys Compd., 574, 504, 2013.

16. HAZIME R., NGUYEN Q.H., FERRONATO C., HUYNH T.K.X., JABER F., CHOVELON J.M. Optimization of imazalil removal in the system $\mathrm{UV} / \mathrm{TiO}_{2} / \mathrm{K}_{2} \mathrm{~S}_{2} \mathrm{O}_{8}$ using a response surface methodology (RSM). Appl. Catal., B, 132133, 519, 2013.

17. NOSHADI I., AMIN N.A.S., PARNAS R.S. Continuous production of biodiesel from waste cooking oil in a reactive distillation column catalyzed by solid heteropolyacid: Optimization using response surface methodology (RSM). Fuel, 94, 156, 2012. 
